\title{
线型旅游体验空间: 风景道的体验性逻理嬗变
}

\author{
张圆刚 ${ }^{1}$, 陈 希 $^{2}$, 余润哲 $^{3}$, 程静静 ${ }^{4}$, 余向洋 $^{4}$
}

(1. 上海师范大学旅游学院, 上海 $200234 ; 2$. 北京体育大学体育休闲与旅游学院, 北京 100084 ;

3. 澳门城市大学国际旅游与管理学院, 中国澳门 999078 ; 4. 黄山学院旅游学院, 黄山 245041)

\begin{abstract}
摘要: 在体验视角下, 风景道不仅只是旅游系统中的旅游过境地或旅游通道, 旅游者逐渐将体 验特色风景道作为出游动机, 同时也折射出旅游产业要素在沿线空间范围上的流向扩散。在 将“在路上”这一旅游体验作为旅游者出游的主要动机, 使传统意义上仅以交通功能承载旅游 流的风景道转向为旅游者体验最直接的表现形式, 并将其整体视为一种特殊类型的旅游目的 地衍生形态, 不仅可以串联各自区隔的旅游空间, 还是我国建立国家公园体系的有效支撑, 同 时也符合全域旅游发展的内在需求。通过对风景道作为新型线性体验空间的合理性进行分 析, 阐述这种旅游目的地衍生形态的理论解析, 并结合国内外相关案例对其特点特征进行总 结。以安徽南部京台高速铜黄段为例, 探讨打造该区域的必然性与重要性, 提出线型旅游体验 空间构建内容,并总结发展内涵上的差异性。线型旅游体验空间的提出, 在理论上深化拓展了 现有关于风景道的旅游研究, 为现实中旅游目的地发展提供一个新的发展方向。
\end{abstract}

关键词: 风景道; 线型旅游体验空间; 逻理嬗变; 安徽

在众多旅游形式中, 自驾游是一种越来越受到旅游者青棟的出游方式, 呈现持续井 喷趋势, 尤其是国家推行国家公园体制试点工程以来，旅游者前往国家公园自驾游所依 托的风景道建设也日益受到重视。我国 “十三五” 旅游业发展规划中明确提出要重点建 设国家风景道体系，将风景道示范工程打造成具有影响力的旅游品牌。在诸多西方国 家, 风景道早已深人人心 ${ }^{[1]}$ 。在我国, 自驾游这种出游形式的悄然风靡在倒逼旅游目的地 思考如何转型的同时，也将人们对风景道的关注提升到前所未有的高度。

克莱尔等 ${ }^{[2]}$ 认为风景道是指具有交通运输和景观欣赏双重功能的通道。余青等 ${ }^{[3]}$ 认 为, 风景道是指旅游和交通功能相结合的、在路旁或视域之内具有景观、游憩、历史、 文化、自然、文物等多重价值的景观道路。传统视角通常将风景道作为道路系统或者旅 游目的地系统中的旅游过境地进行研究, 一直处于旅游目的地的“配角” 地位。

然而，伴随着大众休闲时代的来临，传统的旅游目的地开发模式在一定程度上越来 越难以满足旅游者日益多元化、体验化、品质化的诉求。与此同时, 学术界对风景道的 认知也逐渐跳脱出固有的交通功能与简单景观功能的框架, 尤其是在我国开展国家公园 体制建设试点以来, 道路交通体系特别是风景道作为出人国家公园的主要交通方式之 一, 越来越引起学者们的关注，为其向线型旅游体验空间的嬗变提供了理论基础。

风景道除了被寄予景观上的美学特征以外, 更包含多元功能属性, 通过其在沿线空

收稿日期：2019-03-04；修订日期：2019-09-01

基金项目: 国家自然科学基金项目（41571140); 安徽省哲学社会科学规划项目（AHSKY2018D23); 安徽省社会科 学创新发展研究课题攻关研究项目 (2018CX108)

作者简介: 张圆刚（1982- ), 男, 安徽黄山人, 博士, 副教授, 研究方向为乡村旅游、旅游经济等。

E-mail: 634985206@qq.com

通讯作者：陈希 (1986-), 女, 北京人, 博士, 讲师, 研究方向为体育旅游、旅游者行为等。

E-mail: chenxi0609@sohu.com 
间范围上的延展引导旅游产业生产要素流的流向扩散 ${ }^{[4]}$, 这种显著的辐射效应与 “全域旅 游” 的内涵也不谋而合。在此背景下, 基于风景道的体验功能为研究视角, 结合理论基 础明晰风景道作为新型体验空间乃至一种新兴旅游目的地形态, 即风景道从 “过境地” 向“目的地” 的嬗变过程，是区域旅游发展的现实需求。

本文以风景道为研究对象, 在旅游目的地的系统框架基础上, 将旅游体验理论导人 论证, 延伸出风景道作为一种新兴的、线型的体验空间形式的概念, 将其定义为: 线型 旅游体验空间是以交通功能为基础、以满足旅游者体验需求为根本目的，在风景道及其 辐射范围之内具备多元功能的一种线型的旅游目的地形式。以安徽省南部京台高速铜黄 段区域为案例进行分析，以期在我国其他区域成功推广，并为我国风景道发展提供新的 研究视角与开发切人点。

\section{1 风景道向线型旅游体验空间展演的可能性}

\section{1 线型旅游体验空间的基础一一景道}

风景道是线型旅游体验空间产生的基本雉形。学者们会使用旅游公路、公园道、绿 道、风景小道、文化线路、自驾线路、遗产廊道、风景公路、旅游带、旅游廊道等相似 概念进行研究。虽然对风景道的称法存在差异，但是学者们一致认同的是：基于交通组 织形式的线型空间已经远远超越了从旅游出发地到旅游目的地之间快捷的联通路径这一 基本功能, 而是更加强调视野范围内的景观美化, 以及体验在美景之中驾驶的享受感 ${ }^{[5]}$ 。

风景道体系源于 1995 年美国提出的国家风景道计划, 并随之建立了由泛美风景道、 国家风景道、州级风景道三个层级构成的国家风景道体系。可以说, 美国国家风景道体 系的确立，和美国国家公园的发展是密不可分的，风景道成为串联各大国家公园的最主 要交通方式。随着各国的风景道体系相继发展成熟, 纯粹的美学享受也不再能满足自驾 者对风景道的需求, 道路的休闲、娱乐功能逐步跟进, 直至设计理念改变为融合经济价 值、社会价值、生态价值的综合性、多元化的发展方向。风景道不仅独立成为无数自驾 者的向往, 也是旅游者进人绝大部分国家公园的主要途径。与国家公园体系共同形成 “点一线一面” 的空间发展结构, 是美国旅游体系的核心支撑 ${ }^{[4]}$ 。这也为我国开展国家公 园体制建设试点工程提供借鉴。

目前，国外已经有一批成熟的、有代表性的著名风景道。例如美国的 1 号公路，因 沿途景色优美、串联多个国家公园而闻名于世，所承载的不仅仅是自驾车旅游这一旅游 产品形式，更是 “公路文化” 的具象化体现，它沿途串联比克斯比大桥、大苏尔、十七 英里湾、半月湾州立海滩、赫氏古堡等旅游资源；被誉为美国 “母亲之路” 的 66 号公路 则以沙漠景观和西部风情吸引了自驾车爱好者前往探秘，沿途数个已被荒废遗弃的小镇 也因此得以重生; 行驶在澳大利亚大洋路上可以观赏到十二使徒岩、洛克阿德大峡谷、 伦敦桥等著名旅游景点, 沿途同时串联雨林、牧场、特色小镇等。

在我国, 各地也逐渐开始有意识地重点打造风景道产品, 如 318 国道成都至拉萨段 （川藏线）有 “中国人的景观大道”之誉; 河北省依托坝上优势旅游资源和紧靠北京、天 津的显著区位优势，打造贯通张家口与承德两市的 “国家一号风景大道”，串联塞罕坝、 承德避暑山庄等高等级旅游景区，形成集冬季滑雪、夏季温泉、全年观光休闲等多功能 为一体的旅游经济带。 


\section{2 线型旅游体验空间的理论基础}

道路交通系统一直是旅游学、环境学、地理学、区域经济学研究中的一个重要议 题, 国内外学者较早就围绕旅游风景道、旅游过境地、旅游通道、旅游产业带、公路旅 游等相关概念从不同理论视角进行探讨。

在旅游学科的研究之中, 西方学者较早就已发觉风景道所依托的公路设施对于旅游 系统的重要性。Leiper ${ }^{[6]}$ 早在 1979 年提出的著名旅游系统模型中, 将整体旅游系统划分为 旅游目的地、旅游客源地、旅游通道三大部分，旅游通道因此进人学者们的研究视野。 时至今日, 关于风景道的研究也多是遵循 Leiper 的系统框架。由于旅游的本质离不开 “空间移动”，即从客源地向目的地的移动，而移动中位移现象出现的主要区域集中在旅 游通道部分。因此，风景道承载旅游者 “流动” 衍生出的地理空间分布、开发模式、生 产力布局、区域经济带动、交通客流预测、旅游目的地通达性等问题便成为学者们的主 要研究议题 ${ }^{[7]}$ 。其中, 从道路所具备的基础交通功能来探讨旅游交通对旅游目的地发展的 影响、目的地通达性、旅游交通客流量预测或拥堵治理、旅游交通运输系统对周边生态 影响与破坏以及从旅游规划或城市规划的实践出发进行旅游交通空间优化布局的研究最 为集中 ${ }^{[8-11]}$ 。李东等 ${ }^{[12]}$ 依据 “点一轴” 空间发展理论为基础，系统性地构建 “一带一路” 倡议下中哈边境的旅游产业要素线型空间。但是，在关于旅游目的地系统以及旅游资源 的传统认知观念中, 风景道只被视为游客从旅游客源地到旅游目的地之间的空间移动通 道，并未受到充分重视。

直到近年来，随着自驾游的快速兴起以及旅游者由观光向体验需求升级的巨变，逐 渐出现一种将风景道视作旅游体验重要环节的研究思潮。这种体验视角的研究成果根植 于旅游学界不断对旅游本质的抛问与思考, 认为体验是旅游现象的内核元素，而 “流 动” 这一表象背后的驱动因素是人们希望体验非惯常空间，即从生活世界到旅游世界的 转变 ${ }^{[13]}$ 。体验视角的兴起为风景道作为体验空间提供了良好的理论解释, 越来越多的学 者逐渐认识到风景道亦可以是旅游活动的重要组成部分，甚至是一种旅游资源 ${ }^{[14,15]}$ 。

另一方面, 也有学者将风景道承载的旅游活动作为自驾游产品进行设计研究 ${ }^{[16]}$, 其 内容已经不局限于关于自驾车旅游市场 ${ }^{[17]}$ 、自驾车旅游服务体系 ${ }^{[18]}$ 、自驾旅游者满意度 ${ }^{[19]}$ 、 自驾游线设计等方面 ${ }^{[20]}$ 。原国家旅游局也于 2017 年颁布了《自驾游目的地基础设施与公 共服务指南》( $\mathrm{LB} / \mathrm{T}$ 061-2017), 印证了自驾游旅游产品的生命活力。张朝枝等 ${ }^{[2]}$ 以我国 318 国道为例, 从体验性视角构建了风景道骑行体验模型。余青等 ${ }^{[22]}$ 对美国蓝岭风景道进 行分析, 发现其产品谱系中风景道和游径产品占据主导地位。Ettema 等 ${ }^{[23]}$ 则构建了基于 风景道自驾车旅行的满意度指数。邱海莲等 ${ }^{[24]}$ 曾以哥伦比亚河历史公路作为案例, 率先提 出将风景道延伸成为线型的旅游目的地这一概念的雏形，并探讨了其空间结构的特征。

以上研究成果为风景道作为线型旅游体验空间的可能性推演提供了理论源泉，这些 理论铺垫使得风景道成为旅游资源、旅游景区、旅游目的地的概念深化拓展得以可能。 总体而言，风景道规划或者以线性交通带串联的旅游产业带规划已经在国内外积累了一 定的成功案例, 但较少学者将这一概念上升成为从出游动机的视角进行拓展思辨。

\section{2 “目标”与“过程”的更迭一一景道的体验转向}

\section{1 体验性视角下风景道向旅游目的地衍生形态的嬗变}

早在 20 世纪 70 年代，美国学者克莱尔等 ${ }^{[2]}$ 就率先提出了 “目的地地带” 的理论框 
架, 认为一个旅游目的地系统应包括吸引物综合体、主要通道及出人口、当地社区、内 部连结各旅游要素的通道。最初, 学者们普遍认为旅游目的地应该是具备独立营销推 广、规划策划、产品体系、行政管理、法律框架的实体单元 ${ }^{[3,25]}$ ，因此它甚至应该是可以 被清晰界定行政边界的地理空间 ${ }^{[2]]}$ 。随着相关研究的深人开展, 后续有学者提出旅游目 的地可以脱离行政地理单元, 是一个更加宽泛的知觉的概念, 甚至可以被理解成为旅游 者逗留体验某些地方特色的感知吸引力 ${ }^{[2]}$ 。

关于旅游目的地和以道路为载体的旅游过境地的辨析, 早在 Leiper ${ }^{[6]}$ 的旅游系统模型 中就阐释了旅游目的地与旅游通道的关系。在这一旅游系统中, 旅游目的地是包括吸引 旅游者直接前来游览的核心吸引物的地理空间，而后者则是旅游者从其惯常居住空间往 返旅游目的地之间的通路，即使产生一定旅游消费，也始终处于 “配角” 的角色 ${ }^{[27]}$ 。然 而，随着旅游者对自驾需求的升级，风景道这种传统概念上的旅游过境地也被不断赋予 了新的意义。当旅游者的出游动机是一次难忘的驾驶体验时, 风景道本身就转变成一种 开敞的、线型的旅游目的地, 它将风景道单纯的交通过程转化为旅游者最深刻的特殊旅 游体验方式 ${ }^{[28]}$ 。风景道本身, 或者说, 在风景道上的行驶体验被视为核心吸引物。

以旅游活动主体为逻辑出发点的理论思潮为理解旅游活动的本质开辟了新视野, 旅 游 “体验论” 强调旅游的体验属性才是旅游概念中的核心内涵。旅游体验的产生是由于 旅游者渴望追求环境差异, 重在获得精神层面的满足 ${ }^{[29]}$ 。在我国, 邹统钎等 ${ }^{[30]}$ 、谢彦君 ${ }^{\left[{ }^{[3]}\right.}$ 为丰富完善旅游体验理论也做出很大贡献。谢彦君 ${ }^{[31}$ 认为旅游世界的核心要素就是体 验, 并认为旅游者个体的心理水平与心理结构会因旅游过程中与周边客观环境之间暂时 性的关联而产生变化。

那么, 既然旅游的本意是探寻与惯常环境不一样的远方的话, 这种 “离开” 的整体 路径就构成了旅游的过程，因此旅游的事实被越来越多的旅游者理解成为“在路上” ${ }^{[32]}$ 张进福 ${ }^{[33}$ 也认同 “身体一主体” 论下 “行万里路” 的身体实践全部过程本身即是旅游的 意义之所在。在传统的人地关系中, 旅游目的地依靠特定有形或无形旅游资源作为吸引 物，这些客观存在的旅游资源通过被旅游者观赏游览而被赋予旅游上的游㕰价值。

然而，当将风景道承载的 “在路上” 精神被放大成为一种以行驶体验为核心的旅游 目的地形式时, 旅游者的旅游活动不再是为了某一特定旅游吸引物的 “目标”, 而是追寻 无形的行驶体验 “过程”。甚至有的旅游者只是听闻风景道的知名度，并且为了体验 “在 路上” 的行驶乐趣而产生旅游行为。风景道这种线型空间所承载的旅游流动往往被赋予 “自由” 的展望 ${ }^{[34]}$, 通常是个体的一种自我个性宣泄方式。在西方, 较早就产生了背包客 旅行者形成的公路文化，这些旅行者大多是接受过一定教育程度、有一定可支配收人的 单身年轻人，而 “在路上” 则通常是他们的个性表达方式 ${ }^{[33]}$ 。“在路上” 所追求的开放自 由体验与线型旅游体验空间的构想不谋而合。或者说，在全新的体验视角下，可被体 验、被感知的事物范围被无限扩大。旅游资源得以跳脱出我国《旅游资源分类、调查与 评价》(GB/T18972-2003) 中的范畴, 基于行驶体验的风景道因此也可以被视为一种旅 游资源并上升为核心吸引物，由道路辐射的区域则变成了线型的体验空间。

在厘清体验与风景道这种以交通串联旅游资源的内在关联逻辑后, 可以总结出体验 性视角下由风景道向线型体验空间嬗变的过程大体为: 第一阶段, 串联主要旅游资源, 且具备一定景观观赏功能以及基础旅游服务设施的交通通道。第二阶段，上升为区域旅 游的组成部分之一, 能够满足旅游者的多元化需求，体验性显著提升，经济、生态、人 
文效应逐渐增强。第三阶段, 在风景道的整体驾驶体验或游览体验成为旅游者的出游目 的，风景道不再处于旅游系统中的 “配角” 地位，完成向线型体验空间的嬗变。有别于 传统的旅游景区封闭式开发模式，依托风景道发展而来的线型旅游体验空间线型旅游体 验空间是一种将已有的旅游产品由点状、面状连接成网状的线性空间结构, 可以为旅游 者提供最为直观和深刻的旅游体验。

风景道在欧美国家的发展已有较为深厚的历史。与之相比, 我国风景道出现较晚, 并存在四个主要特征：第一，虽然我国不少省份已经如火如茶的掀起一股风景道建设高 潮，交通运输部等六部门也于 2017 年联合印发了《关于促进交通运输与旅游融合发展的 若干意见》(交规划发〔2017〕24号)，但仍缺乏国家层面的统一管理机构与立法支撑。 第二, 缺乏由国家统一出台的建设标准。第三, 尚未有效引导旅游车辆与社会车辆的分 流。第四，在空间上主要分布于乡村地区，风景道具有较强的经济带动作用，因此对扶 贫增收以及乡村振兴战略的实施具有意义重大。

\section{2 风景道作为线型旅游体验空间的特点}

风景道作为线型旅游体验空间的特征包括以下几个方面:

第一，沿线旅游资源的串联。道路作为交通设施可以上升为线型旅游体验空间的必 备条件就是其串联了多个高等级的旅游资源，同时还需具备优美宜人的沿途景观。因 此，从功能定位上来讲，线型旅游体验空间不仅仅具备道路的基础交通串联功能，而且 是将周边旅游资源进行串联的景观道、文化道，更是带动沿线产业经济发展的旅游产业 带, 具有四位一体的功能特征。这种多元化功能的基础条件是旅游需求的注人, 根源是 旅游者对游览休闲体验的美好向往。

第二，空间上的连续与外推。线型旅游体验空间以风景道所在的道路主体为空间主 轴, 由主轴向两侧延展开来依次是附属设施带、视域带和辐射带。其中, 附属设施带包 括承载自驾车、自行车、徒步等交通旅游组织方式为主的基础设施。附属设施带是指道 路两侧绿化带、边坡、护栏、紧急停车带、观景台等附属设施。视域带是指人们视野所 及的空间范围，这一区域是景观资源的主要展示区，也通常是道路休闲服务设施的分布 区域。辐射带是指周边一定范围内可辐射的旅游景区景点、旅游休闲资源等，通过交通 系统与主道路关联, 同时也可串联大量旅游接待设施、游鄎休闲设施等, 腹地广阔, 经 由定向流动产生的旅游生产要素聚集成旅游产业带, 并最终可以整体形成旅游目的地。 由道路主体与附属设施带组成的基础设施条件决定了空间连续延展性，而空间外推性则 是指由视域带和辐射带构成的向道路两侧外延的广大旅游资源辐射地带 ${ }^{[24]}$

第三，网状的空间开发模式。以风景道为基础的线型旅游体验空间不同于传统的以 核心资源为导向的空间开发模式，受制于空间条件，其接待设施、休闲设施、娱乐设 施、配套服务设施、交通服务系统、经济生产要素等完备程度不足, 所以旅游系统功能 在常态开发模式下无法有效运转。因此, 基于风景道的旅游开发应遵循其自身的空间特 点, 尝试将点状、面状的旅游资源连及旅游产品、服务设施通过交通整体串联成网状的 开发模式 ${ }^{[28]}$ 。

第四，协调沿线的竞合关系。根据合作竞争理论，由于旅游资源之间存在同质性与 差异性, 而以旅游资源为核心的传统发展方式又会形成要素聚集, 因此在一定区域范围 内的各旅游要素之间不可避免地存在一定的竞争与互补合作关系。在传统的旅游目的地 开发过程中, 较为常见的一个弊病是在大空间区域下的各个次级甚至末级开发单位各自 
为政开发出资源相近、功能相似的旅游产品及配套服务, 缺乏统筹观, 进而陷人同质化 竞争的恶性循环。而以风景道为基础的线型旅游体验空间开发要义在于其整体性与连续 性，通过主轴交通与支线交通构成的交通网络将各零散空间组团串联为一个整体，协调 沿线区域的竞争与合作关系 ${ }^{[2]]}$, 在一定程度上克服了传统开发模式中同类资源开发的恶 性竞争问题，并有利于各旅游生产要素之间的功能互补。

3 案例分析: 以安徽南部京台高速铜黄段为例

\section{1 研究区概况}

京台高速（合铜黄高速）铜黄段位于安徽省的南部地区，该路段北起铜陵，南至黄 山, 长约 $173.5 \mathrm{~km}$ 。主体串联区域包括黄山市、池州市、铜陵市，辐射区域可到达宣城 市。该区域内旅游产业高度发达，拥有黄山世界文化与自然遗产以及皖南古村落世界文 化遗产等多个世界级旅游品牌，国际知名度较高，以该区域为案例区的研究成果也不胜 枚举，因此具有良好的代表性与典型性（图 1)。

\section{2 打造线型旅游体验空间的示范项目的重要性}

相比起国内其他区域来说，该案例区具有区域内集中多个世界级的旅游资源，旅游 产品涵盖观光、休闲、度假等多个类型，景观富于变化的优势，并且区域范围适中，具 备良好的开发条件。将其打造成为线型旅游体验空间的示范项目，不仅对将这一新概念 推广到我国其他区域起到借鉴作用，对于集中展现我国优质旅游资源、树立国家旅游品 牌形象来说也具有重要意义。

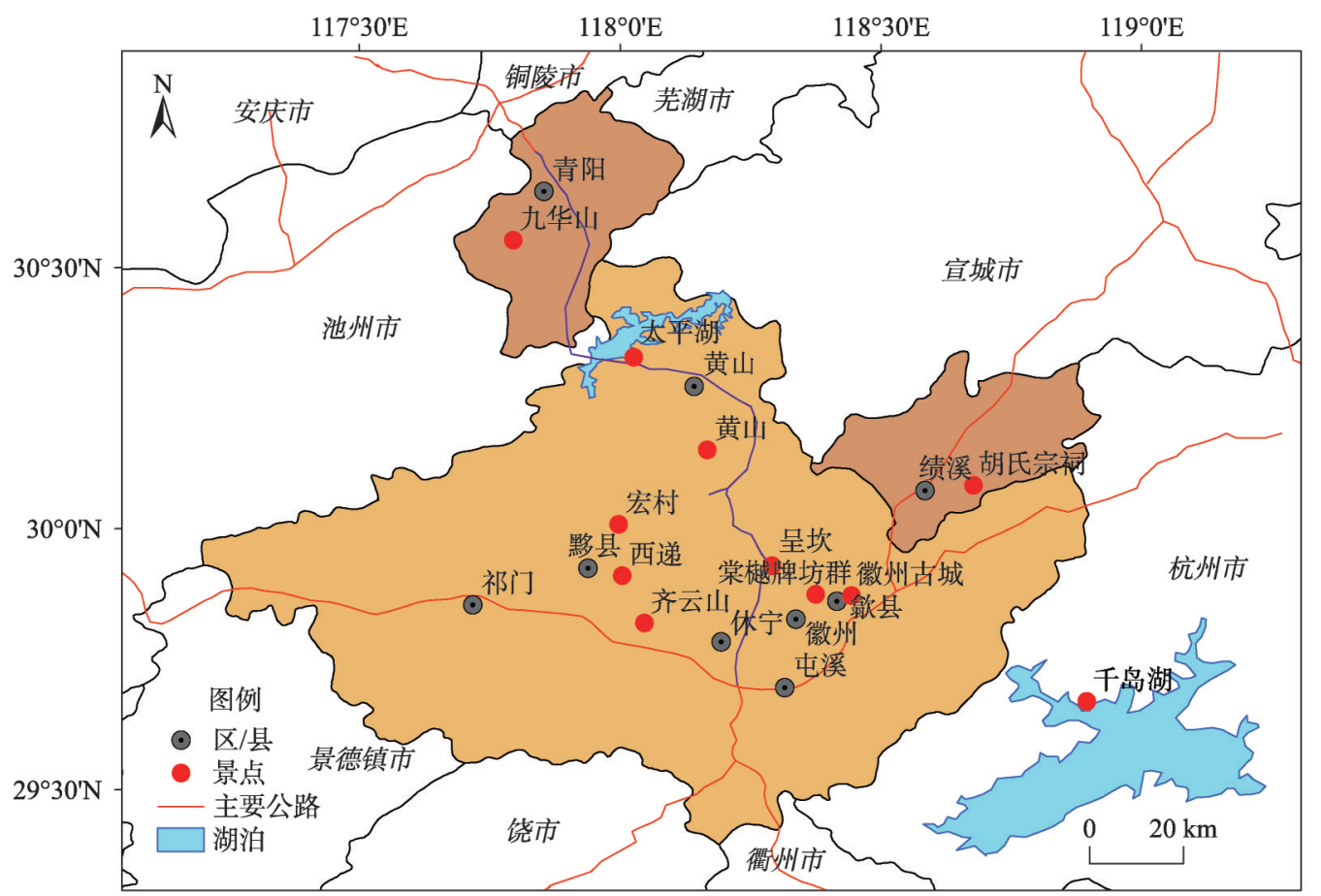

图 1 研究区概况

Fig. 1 Overview of the research area 
第一，主轴道路沿线串联了众多高等级的旅游景区，旅游资源高度密集，沿线自然 景观绝美，文化内涵深厚，从资源禀赋上来说具备打造线型旅游体验示范段的绝佳开发 条件。主轴辐射区域内聚集黄山、西递一宏村、九华山、呈坎、齐云山等闻名中外的旅游 景区。皖南区域也是徽文化的集中体现，完整保留了大量徽派建筑与独特的皖南风土民 情，自然资源与人文资源和谐交织，空间距离适宜，旅游资源组合度高，有很大发展潜力。

第二，在开发上客观受制于皖南山区的地理空间限制，为了保护当地生态环境不宜 大肆建设基础设施。但从另一视角来说，山区沿途景观层次感清晰，山岳的视觉阻挡使 得空间区隔感较高, 景观变化度也随之提高, 便于分段打造, 各段形成较为鲜明的主 题，使驾驶者时刻保持视觉上的新鲜感。

第三，以黄山、九华山、西递、宏村等为主的旅游景区作为核心吸引物积累了庞大 的市场流量。仅以知名度最高的黄山为例, 全市 2017 年旅游接待量达 5777 余万人次, 旅 游总收人超过 500 亿元, 其中人境游客 230 余万人次, 创汇 7.5 亿美元; 而黄山风景名胜 区作为核心吸引物, 吸引着无数海内外游客前来一睹风采, 2017 年共接待游客 336.87 万 人次, 门票收人 5.43 亿元。这些核心旅游景区吸引来的庞大旅游市场达到一定规模后, 自然会形成流动性辐射, 流动的最佳载体就是串联着多个异质性高品质旅游资源的风景 道。流动不仅起到了二次激活市场的功效, 更重要的是促进了市场流、资金流、物质 流、知识流、技术流等生产要素的扩散, 即改变了沿线旅游生产力格局。未来的研究重 点是如何实现旅游生产要素的空间重组, 进而有效带动区域经济整体发展。

第四，以体验为内涵的功能拓展是旅游目的地品牌升级的内在需求。以安徽省目前 的旅游格局来看, 黄山作为旅游增长极的作用从未动摇。当黄山旅游地步人巩固期后, 旅游市场饱和, 需要开发新的产品、塑造新的形象。虽然近年来黄山已经致力于旅游产 品的多元化打造, 但对于广大旅游者来说, 旅游目的地形象仍没有摆脱山岳型观光胜地 的传统形象。因此, 无论是对于黄山市还是对于安徽省旅游发展来说, 都需要培育以体 验为主的多元化旅游产品体系, 调整目的地组织形态, 打造线型旅游体验空间则是十分 切合的突破口。

该区域沿线辐射旅游产品类型多样，囊括了山岳观光、古村落休闲、山水田园等， 行驶过程中可以领略沿途的景观变化, 是感官体验与心灵满足的双重享受, 符合旅游者 “身心合一” 游览体验的基本要求, 因此具有较强示范性。一方面, 打造线型旅游体验空 间示范项目是皖南地区旅游产业发展的必然趋向。另一方面, 我国还有众多与案例区的 背景条件类似的区域, 该示范项目如若打造成功, 也会为其他地区的旅游发展提供一种 新的承载空间形态的思路，通过风景道网状串联各自为政的旅游景区，打破原有边界， 由主轴不断空间外推形成广阔的线型辐射带, 并能够有效协调辐射范围内的旅游资源差 异化发展, 最终助推全域旅游目的地建设。

\section{3 线型旅游体验空间构建}

空间构建的主轴为安徽省京台高速铜黄段的高速公路主体设施，主轴向两侧空间延 伸分别为附属设施带、视域带、辐射带。整体辐射范围涵盖黄山市、池州市、铜陵市、 宣城市内的黄山、西递、宏村、九华山、呈坎、齐云山、太平湖、棠樾牌坊群、徽州古 城、新安江、胡氏宗祠等高等级的旅游资源，其中不乏多个国际级旅游品牌。

目前的旅游空间格局是以黄山为发展极，西递、宏村、九华山等为支撑的多个组团 构成了空间上的 “面”，以及众多次级的旅游景区（景点）构成散落在空间上的“点”, 
相互之间不仅缺乏有效地沟通，还易造成同质化竞争。利用风景道的介人，将点和面进 行有机串联，是对传统开发方式的有效完善和补充。在综合考虑案例区域资源本底、旅 游产业发展现状、交通开发条件等因素的基础上，打造由风景道支撑的兼具交通价值、 风景价值、自然价值、人文价值、历史价值、娱乐价值的线型旅游体验空间。以公路交 通为基础, 完善沿线服务体系, 加强汽车营地、特色镇（村）、步道系统等产业带动，形 成由交通引领旅游发展的网络系统。

在构成线型旅游体验空间架构的风景道线路优化方面，传统的旅游规划多强调打造 旅游环线, 但根据旅游者的实际游览行为习惯来说, 大部分旅游者在进行中远程游览时 会选择两地间的线性通路进行游览，即不再回到出发地。因此，适宜打造成以主轴为轴 心，通过次级公路联通各个景区景点的散射状游线布局，即 “大轴线，小环线” 的交通 组织。在案例地以京台高速铜黄段为主轴, 通过周边风景道与周边各组团相联系, 形成 放射性的交通线网，最终形成 “大轴线，小环线，一中心辐射，四组团串联，多景观路 段，长徒步游径” 的网络空间格局（图 2)。其中，轴线为京台高速主轴，小环线为连接 各组团的风景道, 一中心为大黄山世界遗产发展极, 四组团分别为九华山宗教旅游组 团、太平湖养生度假组团、皖南文化遗产体验组团、徽文化山水体验组团，多景观路段 指由主轴周边风景道系统重点打造的景观路段, 长徒步游径是指沿线规划徒步步道及配 套设施，打造我国首个完善的高品质长距离徒步旅游产品。

\section{4 线型旅游体验空间的打造要点}

3.4.1 体验观主导下由旅游通道向旅游目的地的嬗变过程

体验理论视角下的流动性改变了空间被赋予的意义，其内涵上呈现了 “交通功能与

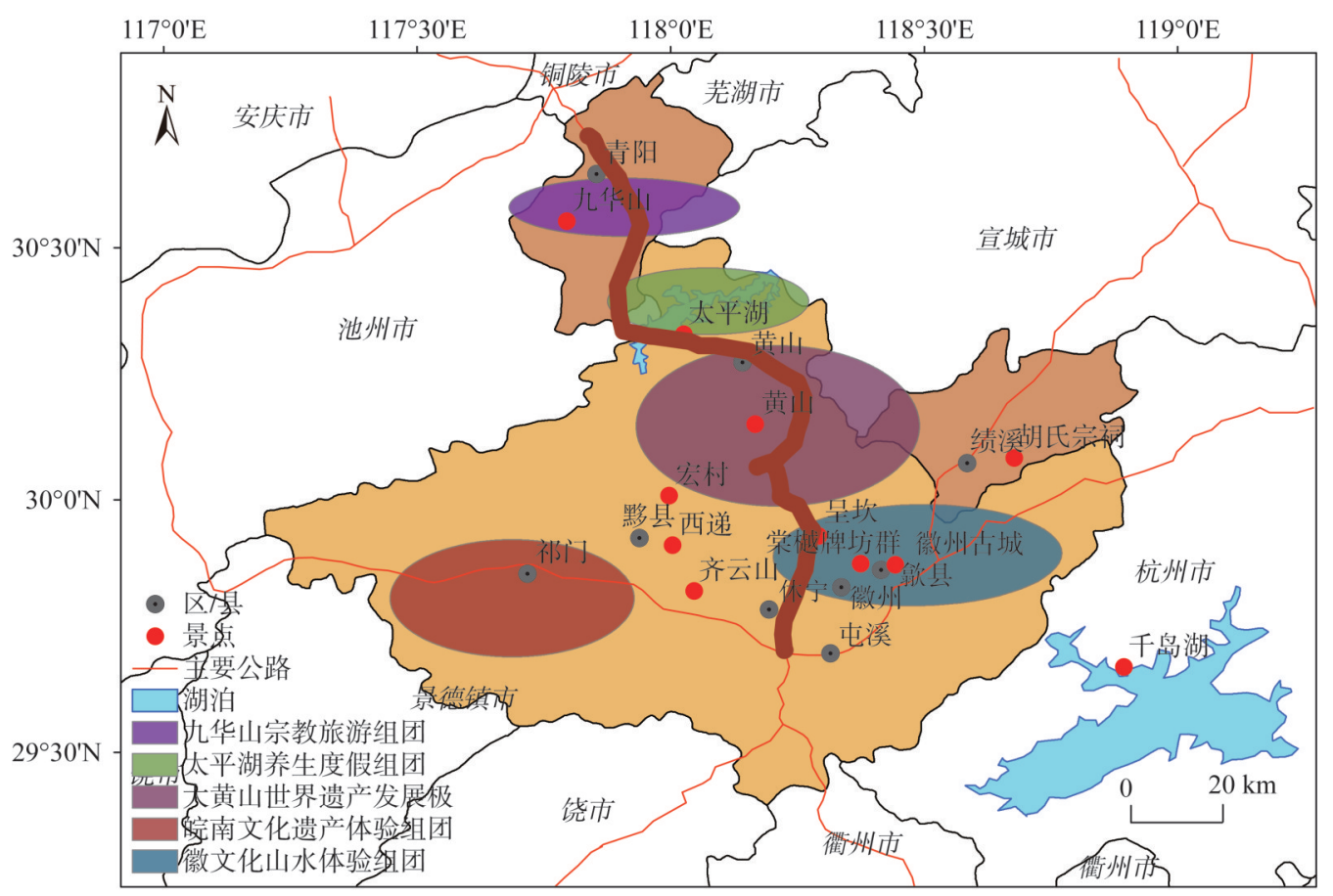

图 2 空间布局

Fig. 2 Space layout diagram 
旅游功能的简单叠加——侧重于具备景观价值的旅游过境地研究——体验视角下的新型 旅游目的地” 的演进嬗变过程。体验使 “在路上” 本身脱离原有的地理空间桎梏上升成 为出游目的。

在体验观主导下，该区域打造线型旅游体验空间的关键点在于培育其以体验为特色 的核心吸引物。第一, 将风景道串联区域整合为一个统一的体验空间, 培育以风景道 为主要载体的旅游体验产品, 整体打造开发, 整体营销宣传。第二, 在项目设计上, 由主轴串联多个风景道和游径产品, 在每一条主要风景道沿线另培育一个或一组重点 项目，并根据所有项目单体的游览时间、活动强度、项目类型进行整体项目布局，优 化全程体验节奏。第三, 结合沿线景观类型、旅游资源特质、道路行驶习惯等因素, 分段打造风景道, 丰富视觉体验层次, 各景观段根据景观特质和地域文化突出不同主 题, 分别为九华山宗教朝圣景观段、太平湖水域风光景观段、大黄山世界遗产景观 段、皖南文化风情景观段、徽文化山水景观段。第四，运用空间叙述的手法设计适合 线型旅游体验空间的轴线叙事方式，向旅游者传达景观背后的地域性、场景性、文化 性的信息，从而增强体验性，使旅游记忆变得独特 ${ }^{[3]}$ 。针对线型这一空间特点，轴线的 叙事元素编排中, 叙事的开端是由轴线的开端开始的, 在整体打造中要注意线型的空 间轮廓、节点之间串联的起承转合、时间与空间脉络的秩序、节奏与韵律的把控、色 彩环境的主题化控制等问题 ${ }^{[3]}$ 。在主要风景道景观路段增添徽文化符号, 铺陈出后续路 程中即将出现的旅游产品; 利用沿线视域带内植被高度和幅度营造视觉效果; 引人水景 观增添行驶中的景观吸引物等, 用以支撑线型旅游体验空间的整体景观效果打造, 避免 景观过度分割而将体验性叙事轴线打乱 ${ }^{[38]}$ 。

另外, 完善线型旅游体验空间作为旅游目的地的旅游设施与相关配套设施, 沿线布 局旅游接待设施、自驾车服务设施以及必要的生活设施。完善基础设施, 尤其在黄山市 休宁县、黟县、徽州区、黄山区、宣城市绩溪县及池州市青阳县境内, 公路交通多为南 北向纵线, 未来可选择条件适宜的东西向县道、小径进行改扩建工程, 将主干道连线。 同时，交通与文化旅游等有关部门应完善相应的管理监督体系。

3.4 .2 各构成要素的开发重点

根据线型旅游体验空间的四个主要特点, 主轴、附属设施带、视域带、辐射带四个 组成要素在开发过程中各自有规划设计侧重点, 功能上互相支撑。

对于主轴和附属设施带来说, 需要通过主轴实现线型旅游体验空间中旅游流快速过 境的基本功能, 因此开发重点是提升交通基础设施及完善服务设施。研究区域地处皖南 山区, 多为山地与丘陵, 对于道路设施的技术要求较高。除了满足交通基本工程技术要 求, 保证安全性之外, 交通功能与景观功能的兼容性也需要纳人考虑, 例如社会车辆与 旅游车辆是否应采取分流等问题。此外，道路交通标识系统的设计、观景台布局、休息 区的设计与文化展示等附属设施的旅游功能植人也是需要思考的因素。

对于沿线视野范围内的视域带来说，开发重点是景观资源的美学提升。视域带是旅 游者行驶进人线性区域后的最直观的视觉体验空间, 也是线型旅游体验空间的连续与外 推特点的重点表象之一, 起到激发旅游者游览兴趣的作用, 是沿线景观设计中艺术创作 的主要承载区。视域带的设计需要考虑到驾驶者在视野范围内所及的一切物体, 包括山 岳、河流湖泊、植被等自然物体和村庄聚落、景观小品、服务设施等人工物体 ${ }^{[5]}$, 进行道 
路两侧的景观控制, 保证重要景观敏感点的视觉通廊的通畅性。相对其他组成部分来 说, 视域带格外需要设计上的艺术表达。在前述各大景观段内进一步重点打造景观条件 好、资源分布密集的示范段，例如：X030 与 Y 102 宏村示范段，该路段辐射西递、宏 村、塔川、木坑竹海等景区景点, 景观特征以皖南古村落、乡村田园风光为主, 一派世 外桃源景象; S103 太平湖示范段的主要展示风姿绰约的太平湖; S 324 与 S215 徽文化示 范段承载了徽州古城、棠栰牌坊群、鲍家花园等众多历史遗迹, 极富人文情怀, 是徽文 化记忆的集中体现；X004 竹县山水示范段位沿新安江畔，如同行驶在一幅山水画卷之中。

道路两侧腹地内的辐射带的开发重点是培育主打旅游产品。通过交通组织形式网状 串联多个高品质、高等级、高影响力的国际旅游品牌，是打造线型旅游体验空间的根本 立足点，同时也是线型旅游体验空间中通过风景道串联沿线旅游资源、协调沿线的竞合 关系、网状空间开发模式这三个特点的集中体现。一方面，从主轴辐射出的地理空间视 角考虑通过交通组织将各旅游产品进行网状串联, 促进生产要素的流动, 进而实现旅游 生产力的优化布局。另一方面，从辐射区域内的重点旅游项目的视角出发，在全线分段打 造各段域内的精品龙头项目，丰富项目内涵，加大营销投人，扩大项目本身的带动能力。

\section{4 结论}

在我国旅游产业转型过程中, 针对自驾游这一庞大的新兴旅游市场, 需要构建与之 相对应的空间形态作为支撑，这种空间形态必然包含以风景道为基础的新型旅游目的 地 ${ }^{[39]}$ 。本文在旅游目的地概念的基础上, 在旅游体验理论、旅游目的地系统模型的理论 指引下, 进一步发展了以风景道为发展基础的线型旅游体验空间的概念, 其产生的必要 条件是串联沿线辐射区域内的旅游资源，其内涵的深层寓意则是旅游者体验视角下 “流 动” 表达的具象形态。可以说，体验既是旅游目的，客观上也是旅游者通过离开惯常环 境进人新奇的非惯常环境过程中完成了地理空间的转换 ${ }^{[40]}$, 其空间承载的内涵与功能的 认知升级则是新的市场环境下旅游者体验升级的结果。随着旅游体验需求的日益增长, 旅游者越来越注重旅游过程中的体验性, 而非仅仅观光游览, 这使得传统的交通环节也 得以成为旅游体验中的重要组成部分, 乃至主要出游目的, 进而促使作为自驾车旅游流 主要承载基础之一的风景道, 通过体验功能的提升与重构, 上升成为自身具备核心吸引 力的线型旅游体验空间。这一过程即是由 “旅游通道” 的辅助角色向深度体验性旅游产 品及线型的旅游目的地衍生形态的嬗变过程及其作为线型特殊空间形态所具有的独特规 律, 一定程度上延展了旅游目的地界定的理论逻辑视角, 是从空间整体性出发对 Leiper ${ }^{\left[{ }^{[6]}\right.}$ 构建的旅游目的地系统模型的突破性诠释。这种体验空间具备串联多个高等级旅游资 源、发展空间上的连续性与外推性、空间开发模式呈网状串联模式、协调沿线旅游产品 及要素间的竞合关系的特征。从现实意义来说, 是风景道旅游体验功能的提升, 培育区 域旅游竞争力的有效途径，也为我国的国家公园体制建设提供了支撑，促进国家公园的 游䄭功能 ${ }^{[41]}$ 。

以安徽省南部京台高速铜黄段区域为案例地，讨论打造线型旅游体验空间示范项目 的可能性，将 “在路上” 的体验培育为核心吸引力，提出了 “大轴线，小环线，一中心 辐射, 四组团串联, 多景观路段, 长徒步游径” 的空间建构, 提出针对主轴及附属设施 带、视域带、辐射带四个组成要素的开发要点。该案例地的打造策略对于在我国推广落 
实线型旅游体验空间概念具有重要意义。

需要说明的是，本文在原有的旅游学科多个理论基础之上发展了线型旅游体验空间 这一概念，旨在指出一种新的理解旅游目的地的视角，因此对此概念的解析尚显浅表， 理论深度有待在后续研究中进一步提升与挖掘, 期望起到抛砖引玉的作用。未来期望收 获更多的理论关注，填补以下领域的研究不足：一是对概念本身的深人探究，给出清晰 定义，形成体系化的完整理论框架；二是风景道对国家公园的生态、经济等方面的影 响; 三是沿线旅游资源的串联方式、开发方式、发展模式、发展层次、发展序列; 四是 基于旅游地理学和旅游规划学视角下的线型旅游体验空间内旅游生产力空间布局模式。

\section{参考文献(References):}

[1] LEW A, MCKERCHER B. Modeling tourist movements: A local destination analysis. Annals of Tourism Research, 2006, 33(2): 403-423.

[2] 克莱尔·冈恩, 特格特-瓦尔. 旅游规划: 理论与案例. 吴必虎, 吴冬青, 党宁 译. 大连: 东北财经大学出版社, 2005. [GUNN C A, TURGUT V. Tourism Planning Theory and Case ( $4^{\text {th }}$ Edition). Translated by WU B H, WU D Q, DANG N. Dalian: Northeast University of Finance and Economics Press, 2005.]

[3] 余青, 㚞欣, 刘志敏, 等. 国外风景道的理论与实践. 旅游学刊, 2006, 21(5): 91-95. [YU Q, FAN X, LIU Z M, et al. On the principle and applicaions of scenic byways abroad. Tourism Tribune, 2006, 21(5): 91-95.]

[4] 王萌萌. 美国旅游公路发展及对我国的启示. 交通运输研究, 2015, 1(4): 8-15. [WANG M M. Development of American scenic byway and its enlightenment to China. Transport Research, 2015, 1(4): 8-15.]

[5] 余青, 吴必虎, 刘志敏, 等. 风景道研究与规划实践综述. 地理研究, 2007, 26(6): 1274-1284. [YU Q, WU B H, LIU Z M, et al. Literature review on scenic byway research and planning practice. Geographical Research, 2007, 26(6): 1274-1284.]

[6] LEIPER N. The framework of tourism: Towards a definition of tourism, tourist, and the tourist industry. Annals of Tourism Research, 1979, 6(4): 390-407.

[7] PRIDEAUX B. The role of the transport system in destination development. Tourism Management, 2000, 21(1): 53-63.

[8] 苏建军, 孙根年, 赵多平. 交通巨变对中国旅游业发展的影响及地域类型划分. 旅游学刊, 2012, 27(6): 41-51. [SU J J, SUN G N, ZHAO D P. The impact of great changes of transportation on the development of China's tourism industry and division of regional types. Tourism Tribune, 2012, 27(6): 41-51.]

[9] 覃文敏, 张小雷, 杨兆萍, 等. 基于路阻函数的旅游交通可达性研究: 以新疆 $3 \mathrm{~A}$ 级及以上级别景区为例. 干旱区研 究, 2015, 32(2): 361-367. [QIN W M, ZHANG X L, YANG Z P, et al. Accessibility of tourism transport based on link performance function: A case of 3A tourism scenic spots in Xinjiang. Arid Zone Research, 2015, 32(2): 361-367.]

[10] 张朝元, 王彭德, 陈丽. 基于 PCA 改进的 LS-SVM 公路旅游客流量预测模型. 昆明理工大学学报: 自然科学版, 2011, 36(5): 38-42. [ZHANG C Y, WANG P D, CHEN L. Forecast model of highway traveling passenger volume based on LS-SVM improved by PCA. Journal of Kunming University of Science and Technology: Natural Science Edition, 2011, 36(5): 38-42.]

[11] MARTIN-CEJAS R R, SANCHEZ P P. Ecological footprint analysis of road transport related to tourism activity: The case for Lanzarote Island. Tourism Management, 2010, 31(1): 98-103.

[12] 李东, 由亚男, 张文中, 等. 中哈边境地区旅游廊道空间布局与发展系统. 干旱区地理, 2017, 40(2): 424-433. [LI D, YOU Y N, ZHANG W Z, et al. Spatial distribution of tourism corridor and development system in the China-Kazakhstan border area. Arid Land Geography, 2017, 40(2): 424-433.]

[13] 马凌, 孙九霞, 朱泣. 流动, 旅游与后现代: 一个研究视角与一种精神转向. 人文地理, 2017, 32(3): 146-151. [MA L, SUN J X, ZHU H. Mobility, tourism and postmodernism: A research perspective and spirituality turn. Human Geography, 2017, 32(3): 146-151.]

[14] 鲁宜苓, 孙根年. 公路何以成为旅游资源. 公路, 2017, 62(3): 193-198. [LU Y L, SUN G N. How highways become tourism resource. Highway, 2017, 62(3): 193-198.]

[15] STANIEK M. Road pavement condition as a determinant of travelling comfort. Intelligent Transport Systems and Travel Behaviour, 2016, 505(7): 99-107. 
[16] 刘军胜, 马耀峰. 西安秦岭自驾游旅游服务质量评价研究. 干旱区资源与环境, 2014, 28(12): 197-202. [LIU J S, MA Y F. Research on the satisfaction of self-driving tourism around the suburbs of Xi'an based on service oriented. Journal of Arid Land Resources and Environment, 2014, 28(12): 197-202.]

[17] 汪德根, 陈田, 刘昌雪. 基于出游半径的自驾车旅游市场特征差异分析: 以苏州市为例. 旅游学刊, 2010, 25(1): 4247. [WANG D G, CHEN T, LIU C X. An analysis of the difference of self-driving tourist market characters based on travel radius: A case study of Suzhou. Tourism Tribune, 2010, 25(1): 42-47.]

[18] 李东和. 旅游目的地自驾车旅游服务体系构建. 旅游学刊, 2012, 27(3): 9-10. [LI D H. Construction of self-driving tourism service system in tourist destinations. Tourism Tribune, 2012, 27(3): 9-10.]

[19] 史春云, 孙勇, 张宏否, 等. 基于结构方程模型的自驾游客满意度研究. 地理研究, 2014, 33(4): 751-761. [SHI C Y, SUN Y, ZHANG H L, et al. Study on the self-drive tourists' satisfaction based on structural equation model. Geographical Research, 2014, 33(4): 751-761.]

[20] 谢飞, 杨扬, 何杰. 基于改良圈算法与线性规划的全国自驾游线路优化研究. 重庆工商大学学报: 自然科学版, 2016, 33(3): 88-93. [XIE F, YANG Y, HE J. Research on the optimization of national self-driving tour route based on modified circle algorithm and linear programming. Journal of Chongqing Technology and Business University: Natural Science Edition, 2016, 33(3): 88-93.]

[21] 张朝枝, 张金金. 流动性的旅游体验模型建构: 基于骑行人藏者的研究. 地理研究, 2017, 36(12): 2332-2342. [ZHANG C Z, ZHANG X. Constructing a mobile travel experience model: Empirical study of cyclists travelling to Tibet. Geographical Research, 2017, 36(12): 2332-2342.]

[22] 余青, 邱海莲. 基于词频的风景道产品谱系: 以美国蓝岭风景道为例. 北京交通大学学报: 社会科学版, 2014, 13(1): 44-49. [YU Q, QIU H L. Product pedigrees of scenic byway based on wording frequency: A case study of blue ridge road. Journal of Beijing Jiaotong University: Social Science Edition, 2014, 13(1): 44-49.]

[23] ETTEMA D, GARLING T, OLSSON L E, et al. The road to happiness: Measuring dutch car drivers' satisfaction with travel. Transport Policy, 2013, 27(5): 171-178.

[24] 邱海莲, 余青. 作为线型旅游目的地的风景道空间结构: 以哥伦比亚河历史公路为例. 转型与重构: 2011 中国城市 规划年会论文集, 2011. [QIN H L, YU Q. Spatial structure of landscape channels as linear tourist destinations: A case study of columbia river historic highway. Transition and Reconstruction: Papers Collection of the 2011 Annual Conference on Urban Planning in China, 2011.]

[25] EKINCI Y, HOSANY S. Destination personality: An application of brand personality to tourism destinations. Journal of Travel Research, 2006, 45(2): 127-139.

[26] BUHALIS D. Marketing the competitive destination of the future. Tourism Management, 2000, 21(1): 97-116.

[27] 杨振之, 陈顺明. 论“旅游目的地”与“旅游过境地”. 旅游学刊, 2007, 22(2): 27-32. [YANG Z Z, CHEN S M. On tourism destination and tourism transit venue. Tourism Tribune, 2007, 22(2): 27-32.]

[28] 李东和, 吴润华, 张莹. 我国风景道研究综述. 资源开发与市场, 2018, 34(2): 292-296. [LI D H, WU R H, ZHANG Y. Review research on scenic byway in China. Resource Development and Market, 2018, 34(2): 292-296.]

[29] DANIEL B. The image: A guide to pseudo-events in America. American Political Science Review, 2013, 59(4): 697-712.

[30] 邹统钎, 吴丽云. 旅游体验的本质、类型与塑造原则. 旅游科学, 2003, 17(4): 7-10. [ZOU T Q, WU L Y. The nature and categories of tourism experiences and developing principles. Tourism Science, 2003, 17(4): 7-10.]

[31] 谢彦君. 基础旅游学. 北京: 中国旅游出版社, 1999. [XIE Y J. Basic Tourism Science. Beijing: China Travel and Tourism Press, 1999.]

[32] 叶超. 在路上: 旅游与哲学关系的思考. 旅游学刊, 2017, 32(11): 3-5. [YE C. On the road: Reflections on the relationship between tourism and philosophy. Tourism Tribune, 2017, 32(11): 3-5.]

[33] 张进福. 身体转向与品质旅游的 “逆向”需求. 旅游学刊, 2018, 33(12): 1-3. [ZHANG J F. The reverse demand of body turn and quality tourism. Tourism Tribune, 2018, 33(12): 1-3.]

[34] COLLIN-LANGE V, BENEDIKTSSON K. Entering the regime of automobility: Car ownership and use by novice drivers in Iceland. Journal of Transport Geography, 2011, 19(4): 851-858.

[35] RILEY P J. Road culture of international long-term budget travelers. Annals of Tourism Research, 1988, 15(3): 313-328.

[36] 肖竞, 曹珂. 基于景观叙事语法与层积机制的历史城镇保护方法研究. 中国园林, 2016, 32(6): 20-26. [XIAO J, CAO K. Historic towns' preservation methodologies based on analysis of landscape narration grammar and historic layering 
mechanism. Chinese Landscape Architecture, 2016, 32(6): 20-26.]

[37] 陈德志. 隐喻与悖论: 空间, 空间形式与空间叙事学. 江西社会科学, 2009, 29(9): 63-67. [CHEN D Z. Metaphor and paradox: Space, spatial form and spatial narratology. Jiangxi Social Sciences, 2009, 29(9): 63-67.]

[38] 魏遐, 白梅, 鞠远江. 基于景观评价的高速公路风景道旅游规划: 以福宁高速风景道为例. 经济地理, 2007, 27(1): 161-165. [WEI X, BAI M, JU Y J. Tourism planning for the scenic speedway based on landscape evaluation: A case study on Funing scenic speed way. Economic Geography, 2007, 27(1): 161-165.]

[39] 张辉. 全域旅游助推自驾旅游. 旅游研究, 2017, 9(4): 2-5. [ZHANG H. Holistic tourism promotes self-driving tourism. Tourism Research, 2017, 9(4): 2-5.]

[40] 黄佩, 王文宏, 张蓁. 网络中的背包客: 从流动中寻求认同. 旅游学刊, 2014, 29(11): 87-94. [HUANG P, WANG W H, ZHANG Z. Backpacker online: Seeking identification from mobility. Tourism Tribune, 2014, 29(11): 87-94.]

[41] 何思源, 苏杨, 王蕾, 等. 国家公园游憩功能的实现: 武夷山国家公园试点区游客生态系统服务需求和支付意愿. 自 然资源学报, 2019, 34(1): 40-53. [HE S Y, SU Y, WANG L, et al. Realisation of recreation in national parks: A perspective of ecosystem services demand and willingness to pay of tourists in Wuyishan Pilot. Journal of Natural Resources, 2019, 34(1): 40-53.]

\title{
The logic transformation of the scenic byway system to the linear experience space transformation
}

\author{
ZHANG Yuan-gang ${ }^{1}$, CHEN Xi ${ }^{2}$, YU Run-zhe ${ }^{3}$, CHENG Jing-jing ${ }^{4}$, YU Xiang-yang ${ }^{4}$ \\ (1. College of Tourism, Shanghai Normal University, Shanghai 200234, China; 2. School of Sport Leisure and \\ Tourism, Beijing Sport University, Beijing 100084, China; 3. Faculty of International Tourism and Management, \\ City University of Macau, Macau 999078, China; 4. School of Tourism, Huangshan University, Huangshan \\ 245041, Anhui, China)
}

\begin{abstract}
From the perspective of traveling experience, the scenic byway is no longer the only tourist transit or tourism passage as experiencing scenic byways has become a new travel motive, which reflects the spatial mobility of tourism industry elements. Regarding "on the road" traveling experience as the major travel motivation of tourists, this paper believes that the scenic byway system performs the function of direct expression of tourists traveling experience rather than the traditional tourism highway system that transits tourist flow. Recognizing the scenic byway system as a special derived form of tourism destination, the paper analyzes the rationality of scenic byway system as a new linear experience space and expounds the theoretical analysis of this derived form of tourist destination. Their characteristics are summarized using relevant domestic and international case studies. Taking the TonglingHuangshan section of the Beijing-Taiwan Expressway in southern Anhui as an example, this paper explores the necessity and importance of developing the scenic byway in the region, proposes the construction components of linear tourism experience space and summarizes the differences in development connotation. The introduction of the linear experience space profoundly expands the existing tourism research on the scenic byway system and provides a new direction for tourist destinations development.
\end{abstract}

Keywords: scenic byway; linear experience space transformation; logic transformation; Anhui 